\title{
The Influence of Educational Robotics to Computational Thinking Skill in Early Childhood Education
}

\author{
Ratih Isnaini $^{1}$, Cucuk Wawan Budiyanto ${ }^{2}$ \\ \{ratihisnaini55@gmail.com ${ }^{1}$, cbudiyanto@ staff.uns.ac.id ${ }^{2\}}$ \\ Postgraduate of Vocational Teacher Education, Universitas Sebelas Maret, Surakarta, Indonesia ${ }^{1}$, \\ Informatics Education Department, Faculty of Teacher Training and Education, Universitas Sebelas \\ Maret, Surakarta, Indonesia ${ }^{2}$
}

\begin{abstract}
Computational Thinking (CT) has been becoming prominent in educational literature for its appeal as an alternative for problem-solving. The teaching of CT skill in secondary and higher education, however, remains the focus of scholarly research in the mainstream databases. A literature review was carried out to examine the use of robots and computational thinking skill in childhood. Three different databases and digital libraries were nominated for their vast number of papers and the wide coverage of readership. Specific keywords applied in the literature analysis were computational thinking and educational robotics to early childhood. This paper amasses the understanding of the impact $\mathrm{CT}$ on education suggested in the literature. The discussion section elaborates the advantage of educational robotics to improve CT skill, various means CT achievement assessment and adoption robotics to improve learning pertinent to early childhood education. Finally, the paper proposes the importance of study CT in early childhood education.
\end{abstract}

Keywords: computational thinking, education robotics, early childhood.

\section{Introduction}

Computational Thinking (CT) is a fundamental skill for everyone and it should be considered as an important component of every child's analytical ability along with reading, writing, and arithmetic[1]. Recently, there has been growing recognition of the importance of $\mathrm{CT}$ in controlling and managing cognitive activities, as well as understanding and solving problems in a wide range of contexts, not only in the field of computer science, but in all disciplines[2] .

Robotics in education is an expansive trend, and at present, more and more educational institutions, ranging from preschool to college, are including robotics in curricula. Many educational robotic platforms spring nowadays, giving the teachers the chance to select the most suitable one for their teaching purposes. Robotics is usually seen as an interdisciplinary activity drawing mostly on science, physics, maths, informatics and technology and offering major new benefits to education in general at all levels. For example, ECEbot, and BOEbot in an engineering course. Regarding remote educational tools, there are several solutions, related to indoor robotics[3], [4], [5].

ICCSET 2018, October 25-26, Kudus, Indonesia

Copyright (C) 2018 EAI

DOI 10.4108/eai.24-10-2018.2280538 
Robotics can be used as a tool that offers opportunities for students to engage and develop computational thinking skills. Educational robotics is being introduced in many schools as an innovative learning environment, enhancing and building higher order thinking skills and abilities, and helping students solve complex problems [6]. Furthermore, a guided instruction approach using robots facilitates teamwork, develops conceptual understanding, enhances critical thinking, and promotes higher-order learning in the domains of mathematics and science [7].

The rapid development of technology in the $21^{\text {st }}$ century, the use of multi-media tool in education has become increasingly popular. Notwithstanding their usual engineering applications, robots are being used more in schools. The children are also playing more with technologically advanced devices during their playtime. Subsequently, studies were conducted to investigate robot use's influence on children's cognition, language, interaction, social and moral development. Recent studies reported that robot use encourages interactive learning, making children more engaged in their learning activities[8]. This increased research on robot application to education needs systematic look at the direction taken this past decade in order to elucidate a roadmap for future studies. A systematic literature review was carried out to examine the use of robots and computational thinking skill in early childhood. The paper synthesizes the findings of research studies carried out in the last ten years and looks at the influence of robots and computational thinking on children and education.

\section{Research Method}

This paper adopted a systematic literature review approach suggested by Okoli and Schabram [9]. An Eight-Step Guide to conducting a systematic literature review. There steps are: the purpose of the literature review; protocol and training; searching for the literature; practical screen; quality appraisal; data extraction; synthesis of studies; and writing the review.

\subsection{Purpose of the literature review}

The first step in any review requires the reviewer to clearly identify the purpose and intended goals of the review. This paper review the influence of education robotics and computational thinking in early childhood.

\subsection{Protocol and training}

For any review that employs more than one reviewer, it is critical that the reviewers be completely clear and in agreement about the detailed procedure to be followed.

\subsection{Searching for the literature}

For this research, three different databases and other digital libraries were selected. There are ScienceDirect, Springer Link, ACM Digital Library and other digital library. To limit the papers to be reviewed, we implemented a search and selection strategy using specific keywords in electronic databases. The following keywords were utilized:"computational thinking", "education robotic", and "early childhood". 


\subsection{Practical screen}

Also known as screening for inclusion, this step requires that the reviewer be explicit about what studies were considered for review, and which ones were eliminated. We reviewed 31 papers from the three databases that match keywords. Table 1, explains the number of papers reviewed from each databases.

Table 1. Bibliographic databases used in this review.

\begin{tabular}{lll}
\hline Bibliographic Database & Database URL & Total \\
\hline ScienceDirect & http://www.sciencedirect.com & 13 \\
ACM Digital Library & http://dl.acm.org & 4 \\
Springer Link & http://link.springer.com & 2 \\
Other & $\ldots$ & 12 \\
Total & & 31 \\
\hline
\end{tabular}

\subsection{Quality appraisal}

In this step, we needs to explicitly spell out the criteria for judging which articles are of insufficient quality to be included in the review synthesis. The criteria of the paper we reviewed were paper reported about computational thinking in education, paper reported about educational robotic in education, and paper reported about computational thingking or education robotic in early childhood. Figure 1, depicted the number of papers reviewed based on search topics. Figure 2, depicted education level of papers reviewed.



Fig. 1. Papers reviewed in study. 


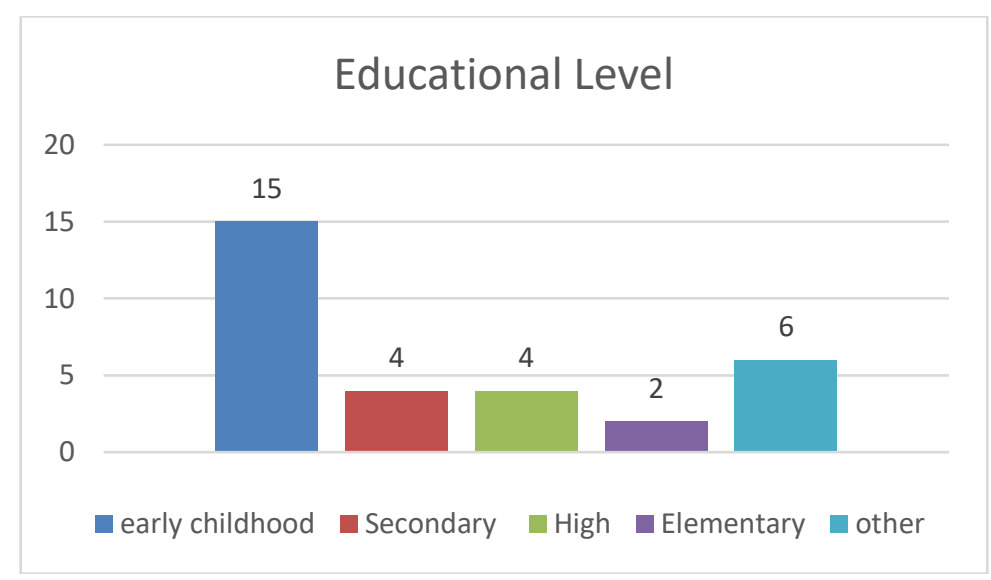

Fig. 2. Education level of paper reviewed.

\subsection{Data extraction}

After all the studies that should be included in the review have been identified, we need to systematically extract the applicable information from each study. In order to construct a comprehensive understanding of the subject, a matrix of concept was built focuses on computational thinking and education robotic. The matrix concept includes the title and name of papers, year of publication, participation, level, delivery, subject, keywords, insight, and themes. In this work, we were extracted from each selected paper. These items provide information to verify the quality criteria and to conduct the synthesis. In what follows, the items are grouped into four categories, which in turn are considered to organize some systematic literature review results and discussion.

\subsection{Synthesis of studies}

In this step involves combining the facts extracted from the studies, then grouping the findings based on the same themes. Formulate findings of the effect of computational thinking and education robotics in early childhood.

\subsection{Writing the review}

Finally, in this step we write find out after review 31 papers in step data extraction and synthesis.

\section{Discussion}

After going through eight-step, the result shows that Computational Thinking and Educational Robotics are integrated into one unit that can improve learning. This is supported by a review of several journals that demonstrate the positive impact of $\mathrm{CT}$ in learning and the advantage of educational robotics to improve CT skill. Then, we also find various means of 
CT achievement assessment. In addition, we also adoption of robotics to improve learning pertinent to early childhood education. The following are some of the themes from the data extraction and synthesis of study phase :

\subsection{The Advantage of Educational Robotics to Improve Computational Thinking Skill}

The high-robotics performance students could solve robotics problems more logically with creativity than the other group[10]. In other interesting thing, robot can also be designed in such a way that can increase CT. Robo Cup Junior (RCJ) has positive impacts on participating students' learning of STEM as well as necessary skills to be successful especially in STEM fields including collaboration and communication skills, computational thinking, and engineering skills[11][12]. And then, Lego Education Wedo also effective to increase the Computational Thinking. The potential of the software Lego Education wedo in the subject of natural sciences to promote the computational thinking, and to engage primary education students in programming, and problem solving is proven [13]. In addition, there is also a software application capable of improving CT. For example is Scartch, this has been proven. Significant improvements related to the concepts of learning, logic, and computational practice with an active approach and, also showing improvements related to computational thinking and computational practice[14]. Using scratch showed that students enjoyed playing with scratchjr and indicated that this programming environment is efficient for the learning of some programming constructs in early childhood and lower level education[15].

\subsection{Various means of Computational Thinking Achievement Assessment}

A pair of online, interactive assessments designed to measures students' computational thinking skills. Form of this assessment can support and measure the computational ideas \& practices that are to central CT. That assessment tool is assessing data analysis skills using motion charts, and assessing modeling and simulations skills with a climate change models[16]. Assessing elementary students' CT in everyday reasoning \& robotics program. The items were contextualized in two types of CT application (coding in robotics and reasoning of everyday events). The instrument has good psychometric properties and has the potential to reveal student learning challenges and growth in terms of CT[17][18]. Many kinds of assessing CT in early childhood education. For example, CT assessment with students learned foundational computational thinking concepts using scratchjr and applied what they learned to creating animation, collages, stories, and games. This technique can show a broad range of what young children learn about computational thinking in classroom interventions using scratchjr than more traditional assessment techniques[19].

\subsection{Educational Robotics to Improve Learning pertinent to Early Childhood Education}

Robotic has a positive impact and many responses indicated that the project was beneficial and educational[20]. Different research, extended the already existing alternative of using the LEGO Mindstorms NXT significantly the effort of a group of professors when preparing exercises and which assess the higher motivational adequacy of using a complete robot in the subjects CSS, CCS, CDAS, RTS [5]. Furthermore, provide LEGO Mindstorms NXT meets the basic education and professional orientation demands of high school students focusing on automation, control systems, robotics, etc [21]. Use the robot as a teaching tool, grounded learning theories can support lessons that are not directly related to Robotics in higher 
education[22]. Besides, ER also efficiently uses in classes on science's subject and math cycle [4]. It is not only that, effects for three subscales (mathematics and scientific investigation, teamwork, social skills) as well as for two main categories (technical skills and soft skills/social aspects) indicated significant[23]. Correlation analysis revealed a number of highly significant strong relations between various sub-scales.

The use of robots for early childhood gives a significant effect[24]. One of them, ER is suitable for progressively improving the ability to plan and control complex tasks in early childhood, encouraging the development of executive function[25]. By engaging in construction-based robotics activities, four-year-olds can play to learn various concepts. As well as, the tangiblek Robotic Program by pairing computer programming and robotics equipment to suit developments with a construction curriculum designed to engage kindergarten children in learning computational thinking, robotics, programming, and problem solving [26]. It is also supported that uses robotics to interest kindergarten children in science and technology [27][12].

Then, robot's influence on children's skills development could be grouped into four major categories: cognitive, conceptual, language and social (collaborative) skills [8]. Interestly in Boston, show that beginning in pre-kindergarten, children were able to master basic robotics and programming skills, while the older children were able to master increasingly complex concepts using the same robotics kit in the same amount of time[28][29].

The behavioral patterns of elementary students and teachers in one-to-one robotics instruction process. The students also significantly tended to play with robots that they themselves designed. The results of this study can be taken into consideration in the design of learning environments with robotics activities[30]. Then the last, Robotics curriculum also effectively is used in a Montessori classroom. Effectiveness robotics curriculum in a Montessori classroom should include materials that emulate traditional Montessori tangibles, a teacher who is comfortable and confident with teaching robotics, and a collaborative student environment [31].

Atmatzidou and Demetriadis have investigated which adobted CT by Wing, this is focused on the basic skills of CT: abstraction, generalization, algorithm, modularity, decomposition and problem solving[1][3][6]. The proposed model encompasses skills that can easily emerge when students engage in educational robotics activities. In detail, the proposed model for CT skills presented in Table 2 . 
Table 2. The CT skills model applied in the current study.

\begin{tabular}{|c|c|c|}
\hline CT skills & Description & Student skills \\
\hline Abstraction & $\begin{array}{l}\text { Abstraction is the process of creating } \\
\text { something simple from something } \\
\text { complicated by leaving out the } \\
\text { irrelevant details, by finding the } \\
\text { relevant patterns, and by separating } \\
\text { ideas from tangible details. }\end{array}$ & $\begin{array}{l}\text { 1. Separate the important from the } \\
\text { redundant information. } \\
\text { 2. Analyse and specify common } \\
\text { behaviours or programming } \\
\text { structures } \\
\text { between different scripts. } \\
\text { 3. Identify abstractions between } \\
\text { different programming } \\
\text { environments. }\end{array}$ \\
\hline Generalisation & $\begin{array}{l}\text { Generalization is transferring a } \\
\text { problem-solving process to a wide } \\
\text { variety of problems. }\end{array}$ & $\begin{array}{l}\text { Expand an existing solution in a given } \\
\text { problem to cover more } \\
\text { possibilities/cases }\end{array}$ \\
\hline Algorithm & $\begin{array}{l}\text { Algorithm is a practice of writing step- } \\
\text { by-step, specific and unambiguous, } \\
\text { instructions for carrying out a process. }\end{array}$ & $\begin{array}{l}\text { 1. Explicitly state the algorithm } \\
\text { steps. } \\
\text { 2. Identify different effective } \\
\text { algorithms for a given problem. } \\
\text { 3. Find the most efficient algorithm. }\end{array}$ \\
\hline Modularity & $\begin{array}{l}\text { Modularity is the development of } \\
\text { autonomous processes, which } \\
\text { encapsulate a set of often used } \\
\text { commands that perform a specific } \\
\text { function and might used in the same or } \\
\text { different problems }\end{array}$ & $\begin{array}{l}\text { Develop autonomous sections of } \\
\text { code to be used for the same or } \\
\text { different problems }\end{array}$ \\
\hline Decomposition & $\begin{array}{l}\text { Decomposition is the process of } \\
\text { breaking problems down into smaller } \\
\text { parts that may be more easily solved }\end{array}$ & $\begin{array}{l}\text { Break down a problem into } \\
\text { smaller/simpler parts that are easier to } \\
\text { manage }\end{array}$ \\
\hline
\end{tabular}

Computational Thinking has benefits and advantages in general. CT also important in education and teaching practice, specifically at years $1-13$, and note areas which this is currently being implemented[32]. Besides, teachers bringing CT lesson in their science classrooms[33]. The result: CT approach is effective at reaching diverse audience and being easily adopted by in-service teacher. Then, creating more activities, and finding more ways to increase existing lesson plans with CT practices will further improve learners CT in mathematics \& science abilities[34]. CT can also developed for early childhood. Students in three second grade classrooms learned foundational computational thinking concepts using Scratchjr and applied what they learned to creating animated collages, stories, and games. The students can showcase a broad range of computational thinking concepts as they demonstrate and talk about their personally meaningful Scratchjr projects [35]. After reviewed, can show that $\mathrm{CT}$ and robotic giving positive impact in learning. CT also effective in mathematics and sciences subject.

The results suggest that the students became familiar with the concepts of CT and integrate them into a satisfactory extent in the process of problem solving in Education Robotics (ER) activities[1].

On the other hand, evidently in utilization of robot can increase CT skill too. The preengineering students could enhance robotics performance, that their computational thinking process was promoted through its component of logical thinking, problem-solving and creative thinking. Interestingly, the high-robotics performance, students could solve robotics problems more logically with creativity than the other group[17]. 
Broadly speaking, the application of robotics in science and technology learning has a significant influence that can improve learning and motivate children in learning, but research on the effectiveness of education robotic for early childhood is still rare. Considering that the assessment of the learning process is further study is important and needed. Besides, education robotic and CT showed a connection that the ER could be used to improve CT skills, but the application of early childhood still did not exist. Given the significant influence and positive impact of CT and ER on learning, there is still a need for further research on the effectiveness of the merger between ER and CT when applied in early childhood learning.

\section{Conclusion}

This paper collects an understanding of the impact of CT on education suggested in the literature. We reviewed 31 papers from three different digital databases and other libraries. There are ScienceDirect, Springer Link, ACM Digital Library and other Digital Library. From the results of the review, we can show the benefits of robotics education to improve CT skills, various CT assessment methods, the adoption of robotics to improve learning related to early childhood education and the positive impact of CT on learning,

Literature review which shows that Robotics Computing and Education can be a single unit that influences learning. Computational Thinking has a positive effect on learning, both in the subject of robotics and science subjects. The use of robots also has a significant influence and motivates students in learning. In addition, educational robotics can improve CT skill student. So, it can be concluded that Computing Thinking in early childhood education is very important and necessary. In the future, there needs to be research on the implementation of education to improve ct skills in early childhood and effectiveness educational robotic to computational thinking skills in early childhood.

\section{Acknowledgment}

Thanks to Postgraduate of Vocational Teacher Education Universitas Sebelas Maret and Universitas Sebelas Maret and Informatics Education Department, Faculty of Teacher Training and Education, Universitas Sebelas Maret that gives us the sponsorship for our research.

\section{References}

[1] S. Atmatzidou and S. Demetriadis, "Advancing students' computational thinking skills through educational robotics: A study on age and gender relevant differences," Rob. Auton. Syst., vol. 75, pp. 661-670, 2016.

[2] J. M. J. M. Chambers, M. Carbonaro, M. Rex, and S. Grove, "Scaffolding Knowledge Construction through Robotic Technology : A Middle School Case Study,” ... Technol. ..., vol. 6, pp. 55-70, 2007.

[3] S. Atmatzidou and S. Demetriadis, "How to Support Students ' Computational Thinking Skills in Educational Robotics Activities," Proc. 4th Int. Work. Teach. Robot. Teach. with Robot. 5th Int. Conf. Robot. Educ., pp. 43-50, 2014.

[4] E. Ospennikova, M. Ershov, and I. Iljin, "Educational Robotics as an Inovative Educational Technology," Procedia - Soc. Behav. Sci., vol. 214, no. June, pp. 18-26, 2015.

[5] A. Cruz-Martín, J. A. Fernández-Madrigal, C. Galindo, J. González-Jiménez, C. StockmansDaou, and J. L. Blanco-Claraco, "A LEGO Mindstorms NXT approach for teaching at Data Acquisition, Control Systems Engineering and Real-Time Systems undergraduate courses," Comput. 
Educ., vol. 59, no. 3, pp. 974-988, 2012.

[6] J. M. Wing, "Computational thinking and thinking about computing," Philos. Trans. R. Soc. A Math. Phys. Eng. Sci., vol. 366, no. 1881, pp. 3717-3725, 2008.

[7] S. Blanchard, V. Freiman, and N. Lirrete-Pitre, "Strategies used by elementary schoolchildren solving robotics-based complex tasks: Innovative potential of technology," Procedia - Soc. Behav. Sci., vol. 2, no. 2, pp. 2851-2857, 2010.

[8] A. Toh et al., "A Review on the Use of Robots in Education and Young Children A Review on the Use of Robots in Education and Young Children," J. Educ. Technol. Soc., vol. 19, no. 192, pp. 148-163, 2016.

[9] C. Okoli and K. Schabram, "A Guide to Conducting a Systematic Literature Review of Information Systems Research,” Work. Pap. Inf. Syst., vol. 10, no. 26, pp. 1-51, 2010.

[10] S. Hutamarn, S. Chookaew, C. Wongwatkit, S. Howimanporn, T. Tonggeod, and S. Panjan, "A STEM Robotics Workshop to Promote Computational Thinking Process of Pre- Engineering Students in Thailand: STEMRobot," 25th Int. Conf. Comput. Educ., no. December, pp. 514-522, 2017.

[11] A. Eguchi, "RoboCupJunior for promoting STEM education, 21st century skills, and technological advancement through robotics competition," Rob. Auton. Syst., vol. 75, pp. 692-699, 2016.

[12] P. M. Özturan*, A. Bozanta, B. Basarir-Ozel, E. Akar, and M. Coşkun, "A cross-generational robotics project day: pre-school children, pupils and grandparents learn together," Int. J. Manag. Sci. Inf. Technol., vol. 17, no. 17, pp. 1-23, 2015.

[13] A. M. Pinto-Llorente, S. C. Martín, M. C. González, and F. J. García-Peñalvo, "Developing computational thinking via the visual programming tool," Proc. Fourth Int. Conf. Technol. Ecosyst. Enhancing Multicult. - TEEM '16, pp. 45-50, 2016.

[14] J. M. Sáez-López, M. Román-González, and E. Vázquez-Cano, "Visual programming languages integrated across the curriculum in elementary school: A two year case study using 'scratch' in five schools," Comput. Educ., vol. 97, pp. 129-141, 2016.

[15] S. Papadakis, M. Kalogiannakis, and N. Zaranis, "Developing fundamental programming concepts and computational thinking with ScratchJr in preschool education: a case study," Int. J. Mob. Learn. Organ., vol. 10, no. 3, p. 187, 2016.

[16] D. Weintrop et al., "Interactive Assessment Tools for Computational Thinking in High School STEM Classrooms," Lect. Notes Inst. Comput. Sci. Soc. Telecommun. Eng. LNICST, vol. 136 LNICST, pp. 22-25, 2014.

[17] G. Chen, J. Shen, L. Barth-Cohen, S. Jiang, X. Huang, and M. Eltoukhy, "Assessing elementary students' computational thinking in everyday reasoning and robotics programming," Comput. Educ., vol. 109, pp. 162-175, 2017.

[18] B. Zhong, Q. Wang, J. Chen, and Y. Li, An Exploration of Three-Dimensional Integrated Assessment for Computational Thinking, vol. 53, no. 122. 2015.

[19] D. D. J. Portelance and M. U. M. Bers, "Code and Tell: Assessing Young Children's Learning of Computational Thinking Using Peer Video Interviews with ScratchJr," Proc. 14th Int. Conf. Interact. Des. Child., pp. 271-274, 2015.

[20] S. B. Lee and H. Lovvorn, "Building computational thinking skills using robots with first-year engineering students," vol. 2016-June, 2016.

[21] S. A. Filippov, A. L. Fradkov, and B. Andrievsky, Teaching of robotics and control jointly in the university and in the high school based on LEGO Mindstorms NXT, vol. 18, no. PART 1. IFAC, 2011.

[22] N. Spolaôr and F. B. V. Benitti, "Robotics applications grounded in learning theories on tertiary education: A systematic review," Comput. Educ., vol. 112, pp. 97-107, 2017.

[23] M. Kandlhofer and G. Steinbauer, "Evaluating the impact of educational robotics on pupils' technical- and social-skills and science related attitudes," Rob. Auton. Syst., vol. 75, pp. 679-685, 2016.

[24] S. Filippov, N. Ten, I. Shirokolobov, and A. Fradkov, "ScienceDirect Robotics in Secondary School Teaching Robotics in Secondary School," IFAC-PapersOnLine, vol. 50, no. 1, pp. 12155- 
$12160,2017$.

[25] M. C. Di Lieto et al., "Educational Robotics intervention on Executive Functions in preschool children: A pilot study," Comput. Human Behav., vol. 71, pp. 16-23, 2017.

[26] M. U. Bers, "The TangibleK robotics program: Applied computational thinking for young children," Early Child. Res. Pract., vol. 12, no. 2, pp. 1-20, 2010.

[27] M. U. Bers and M. Portsmore, "Teaching partnerships: Early childhood and engineering students teaching math and science through robotics," J. Sci. Educ. Technol., vol. 14, no. 1, pp. 5973, 2005.

[28] A. Sullivan and E. R. Kazakoff, "The Wheels on the Bot go Round and Round: Robotics Curriculum in Pre-Kindergarten," J. Inf. Technol. Educ. Innov. Pract. Cite J. Inf. Technol. Educ. Innov. Pract., vol. 12, no. 12, pp. 203-219, 2013.

[29] A. Sullivan and M. U. Bers, "Robotics in the early childhood classroom: learning outcomes from an 8-week robotics curriculum in pre-kindergarten through second grade," Int. J. Technol. Des. Educ., vol. 26, no. 1, pp. 3-20, 2016.

[30] S. Kucuk and B. Sisman, "Behavioral patterns of elementary students and teachers in one-toone robotics instruction," Comput. Educ., vol. 111, pp. 31-43, 2017.

[31] M. Elkin, A. Sullivan, and M. U. Bers, "Implementing a Robotics Curriculum in an Early Childhood Montessori Classroom," J. Inf. Technol. Educ. Innov. Pract., vol. 13, pp. 153-169, 2014.

[32] M. Mohaghegh and M. Mccauley, "Computational Thinking: The Skill Set of the 21st Century Computational Thinking: The Skill Set of the 21 st Century," Int. J. Comput. Sci. Inf., no. June, pp. 1524-1530, 2016.

[33] M. U. Bers, L. Flannery, E. R. Kazakoff, and A. Sullivan, "Computational thinking and tinkering: Exploration of an early childhood robotics curriculum," Comput. Educ., vol. 72, pp. 145$157,2014$.

[34] K. Orton, D. Weintrop, E. Beheshti, K. Jona, M. Horn, and U. Wilensky, "Bringing computational thinking into the high school mathematic and science classrooms," American, pp. 705-712, 2013.

[35] D. J. Portelance, A. L. Strawhacker, and M. U. Bers, "Constructing the ScratchJr programming language in the early childhood classroom," Int. J. Technol. Des. Educ., vol. 26, no. 4, pp. 489-504, 2016. 